\title{
Toward a rich phonology
}

Robert Port

Departments of Linguistics and Cognitive Science, Indiana University, USA

https://doi.org/10.36505/ExLing-2006/01/0059/000059

\begin{abstract}
A radically new conception of linguistic representations is proposed. The claim is that language is stored in memory in the form of large distributions of specific utterances in a rich high-dimensional space, sometimes called exemplar memory. This is the form the brain uses for understanding and creating utterances in real time. In contrast, the abstract, speaker-independent description of language (as modelled by alphabetical orthographies and by linguistic descriptions using phonemes, etc.) exhibits many structures and patterns that comprise a social institution, maintained by speakers over time, and approximating a discrete system made from components. However, these phenomena, shaped by social as well as articulatory/auditory factors, play no clear role in real-time language processing.
\end{abstract}

\section{The traditional view}

For about a century, linguists have trusted their intuitions that speech presents itself to our consciousness in the form of segments, that is, consonant or vowel units (Saussure, 1916; Jones, 1918, p. 1; Ladefoged, 1972; IPA, 1999) but these powerful intuitions may be partially (or wholly) a result of the lifelong literacy training to which all readers of this paragraph have been subjected. The vast majority of experimental evidence supports a very rich memory for language (resembling our detailed and contextsensitive memory for everyday events and activities, Nosofsky, 1986; Shiffrin and Steyvers, 1997), not a memory that uses abstract, speakerindependent tokens in serial order. However, the abstract, phoneme-based view has prevailed in the field despite many kinds of evidence against it.

\section{Counterevidence}

The most powerful evidence that words are not represented in memory using a phonology-like code consisting of segments (represented by letters) and features is found in recognition memory experiments. Linguistic theory predicts that words will be remembered in "linguistic form", that is, they will be stored using abstract, serially ordered "spellings" in phonological units. So, if we hear someone say tomato, then what is supposedly stored and what should influence later cognitive tasks (such as recognizing the repetition of a word) should be some phonological spelling of, say, tomato. Details about the specific utterance, such as the identity and sex of the

ExLing 2006: Proceedings of 1st Tutorial and Research Workshop on Experimental Linguistics, 28-30 August 2006, Athens, Greece 
speaker or the timing pattern of the pronunciation should not be stored (Halle, 1985). But there is persuasive evidence that speaker identity and timing patterns do influence performance on a recognition memory task (Goldinger, 1996; Palmeri, et al, 1993). For example, if a subject hears a list of spoken words and is asked to indicate when a word is repeated in the list, accuracy naturally declines the greater the amount of time between the first presentation and the second. But if this is done with a list pronounced by a variety of voices, then words that are repeated in the same voice as the first are recognized about $8 \%$ more accurately than when repeated in a different voice. The improvement lasts for up to a week. This implies that speakers store much richer and more detailed representations than linguists thought.

Many other well-known phenomena related to speech perception are compatible with the view that the form of word storage is highly concrete and detailed, that is, approximately an "exemplar memory." For example, the formidable problem of "coarticulation" - the problem of how speakers "hear" speech as though it consists of nonoverlapping, context-free segments when the auditory stimulus has a great deal of temporal overlap and context-sensitive variation (Kent and Minifie, 1977) disappears with rich memory. The answer is that memory does not extract an abstract, contextfree invariant for each consonant and vowel. It is only the intuitions of someone trained to read and write using an alphabet that find a problem here (Morais, et al, 1979; Rayner, et al, 2001). Similarly, short-term memory or the so-called "phonological loop" (Baddeley, 1986), appears to be a motor store, something very concrete and sensitive to context and not an abstract, static code (Wilson, 2001). Further evidence comes from incomplete neutralization (Port and Leary, 2005) and the apparently continuous variation in sound change (Labov, 1963).

All these sources of evidence imply a speech memory that stores huge amounts of speech material coded by an extremely rich auditory code that is sure to differ in detail from person to person. It also implies that the notion of contrast plays no role whatever in linguistic memory. We seem to remember whatever we can about all details of specific utterances. Abstractions and generalizations can be easily extracted as needed from a memory containing concrete instances (Hintzman, 1986).

\section{Rich phonology}

If words are stored in this detailed and indeterminate way, then how can linguistic description be done? The answer proposed here is that phonological patterns have little to do with the memory structure of speech (despite our linguistic intuitions favoring alphabetical descriptions). Phonological patterns are found in the corpus of speech by some community. The linguist looks across a large set of utterances and, using whatever 
Toward a rich phonology 263

descriptive tools may be available, describes the patterns found there. This corpus is, of course, the ambient language as it presents itself to the language learner. Some of these patterns (most of the traditional phonological phenomena involving phonemes, features, syllables, etc.) can be described using an alphabet of phonetic symbols. Other patterns require more careful measurements of time or frequency (e.g., voice-onset time, mora patterns, formant transitions, spectrum shapes, intonation contours, etc.). Both kinds of descriptions aim to capture (a) the properties that make one language different from another and that (b) represent distinctions that are exploited by speakers of the language to differentiate various sets of lexical items. Such descriptions will be essential tools for teaching a new language to adult speakers of another language and provide a practical basis for development of an orthography (in cases where one is needed). But neither description should be assumed to play much of a role in the realtime perception and production of speech.

If speech memory is so much richer than we thought, then why, one might ask, do languages have phonological systems at all? And why do small alphabets work as well as they do for recording them? The answer is not completely clear, but over time the language as institution is shaped by users toward a system with limited degrees of freedom. Presumably such a system is easier to learn and to understand and may facilitate creating new words. But this does not imply that the apparent "units" of this schematic phonology are units in human memory for language.

\section{Conclusions}

The story being told here represents a radical break with the past. It is asserted that the powerful intuitions we have relied upon for a century that language manifestly has a segmental structure in terms of discrete letter-like units are primarily the consequence of our literacy education. We were taught to listen to and think about language in segmental terms because these skills are what is demanded for skillful use of our orthography. Consequently we insisted the "real" structure of language is discrete and segmental too despite all the contrary evidence. The discipline of phonology cannot, as linguists from Saussure to Chomsky and Halle had hoped, be both a description of the psychological code for language in memory and also be a communicable description of our language suitable for writing and teaching to others.

\section{Acknowledgements}

Thanks to David Pisoni, Susannah Levi and Mark Van Dam for discussion. 


\section{References}

Baddeley, A. D. 1986. Working Memory. Oxford, U. K.: Oxford University Press.

Chomsky, N., and Halle, M. 1968. The Sound Pattern of English. New York: Harper and Row.

Goldinger, S. D. 1996. Words and voices: Episodic traces in spoken word identification and recognition memory. Journal of Experimental Psychology: Learning, Memory and Cognition, 22, 1166-1183.

Halle, M. 1985. Speculations about the representation of words in memory. In V. Fromkin (Ed.), Phonetic Linguistics: Essays in Honor of Peter Ladefoged (pp. 101-114). Orlando, Florida: Academic Press.

Hintzman, D. L. 1986. 'Schema abstraction' in a multiple-trace memory model. Psychological Review, 93, 411-428.

IPA. 1999. Handbook of the International Phonetic Association: A Guide to the Use of the International Phonetic Alphabet. Cambridge, England: Cambridge University Press.

Jones, D. 1918. An Outline of English Phonetics. Leipzig, Germany: Teubner.

Ladefoged, P. 1972. A Course in Phonetics. Orlando, Florida: Harcourt Brace Jovanovich.

Nosofsky, R. 1986. Attention, similarity and the identification-categorization relationship. Journal of Experimental Psychology: General, 115, 39-57.

Kent, R. and Minifie, F. 1977. Coarticulation in recent speech production models. Journal of Phonetics 5, 115-135.

Labov, W. 1963. The social motivation of a sound change. Word, 19, 273-309.

Morais, J., Cary, L., Alegria, J., and Bertelson, P. 1979. Does awareness of speech as a sequence of phones arise spontaneously? Cognition, 7, 323-331

Palmeri, T. J., Goldinger, S. D., and Pisoni, D. B. 1993. Episodic encoding of voice attributes and recognition memory for spoken words. Journal of Experimental Psychology, Learning, Memory and Cognition, 19, 309-328.

Port, R. F., and Leary, A. 2005. Against formal phonology. Language, 81, 927-964.

Port, Robert 2006 (under review). Words, symbols and rich memory. New Ideas in Psychology.

Rayner, K., Foorman, B., Perfetti, C., Pesetsky, D., and Seidenberg, M. 2001. How psychological science informs the teaching of reading. Psychological Science in the Public Interest, 2, 31-74

Saussure, F. d. 1916. Course in General Linguistics (W. Baskin, Trans.). New York: Philosophical Library.

Shiffrin, R., and Steyvers, M. 1997. A model for recognition memory: REM: Retreiving effectively from memory. Psychonomic Bulletin and Review, 4, 145166.

Wilson, M. 2001. The case for sensorimotor coding in working memory. Psychonomic Bulletin and Review, 8, 44-57. 